This item was submitted to Loughborough's Institutional Repository (https://dspace.lboro.ac.uk/) by the author and is made available under the following Creative Commons Licence conditions.

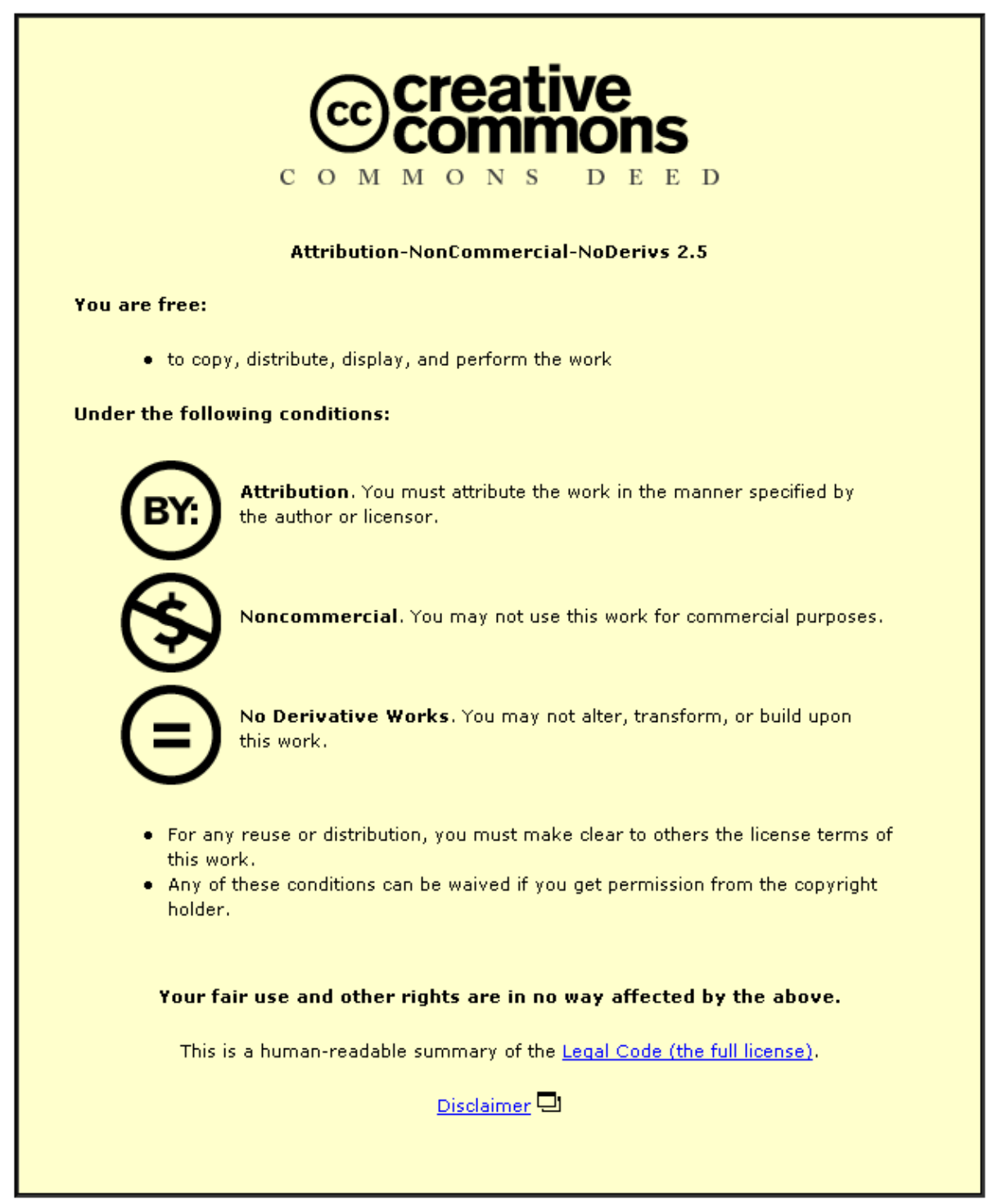

For the full text of this licence, please go to: http://creativecommons.org/licenses/by-nc-nd/2.5/ 


\title{
Modeling the dynamics of soil erosion and size-selective sediment transport over nonuniform topography in flume-scale experiments
}

\author{
B. C. P. Heng, ${ }^{1}$ G. C. Sander, ${ }^{2}$ A. Armstrong, ${ }^{3}$ J. N. Quinton, ${ }^{4}$ J. H. Chandler, ${ }^{2}$ and C. F. Scott ${ }^{2}$ \\ Received 31 March 2010; revised 6 November 2010; accepted 17 November 2010; published 10 February 2011.
}

[1] Soil erosion and the associated nutrient fluxes can lead to severe degradation of surface waters. Given that both sediment transport and nutrient sorption are size selective, it is important to predict the particle size distribution (PSD) as well as the total amount of sediment being eroded. In this paper, a finite volume implementation of the Hairsine-Rose soil erosion model is used to simulate flume-scale experiments with detailed observations of soil erosion and sediment transport dynamics. The numerical implementation allows us to account for the effects of soil surface microtopography (measured using close range photogrammetry) on soil erosion. An in-depth discussion of the model parameters and the constraints is presented. The model reproduces the dynamics of sediment concentration and PSD well, although some discrepancies can be observed. The calibrated parameters are also consistent with independent data in the literature and physical reason. Spatial variations in the suspended and deposited sediment and an analysis of model sensitivity highlight the value of collecting distributed data for a more robust validation of the model and to enhance parametric determinacy. The related issues of spatial resolution and scale in erosion prediction are briefly discussed.

Citation: Heng, B. C. P., G. C. Sander, A. Armstrong, J. N. Quinton, J. H. Chandler, and C. F. Scott (2011), Modeling the dynamics of soil erosion and size-selective sediment transport over nonuniform topography in flume-scale experiments, Water Resour. Res., 47, W02513, doi:10.1029/2010WR009375.

\section{Introduction}

[2] Soil erosion and the subsequent transport of sediment by overland flow can have adverse effects on surface water quality. It is well known that clay and silt particles are preferentially transported by overland flow [Parsons et al., 1991; Sutherland et al., 1996; Leguédois and Le Bissonnais, 2004]. These particles carry with them high concentrations of sorbed nutrients and other potentially deleterious elements [Sharpley, 1980; McDowell et al., 1989; Zhang et al., 2003; Quinton and Catt, 2007]. Thus, it is important, in trying to model the effects of soil erosion on surface water quality, to predict not just total sediment fluxes but also the particle size distribution (PSD) of the eroded sediment.

[3] There are a number of size-selective erosion models in the literature [e.g., Woolhiser et al., 1990; Hairsine and Rose, 1991, 1992a, 1992b; Flanagan and Nearing, 1995; De Roo et al., 1996]. With the exception of the HairsineRose (H-R) model, all adopt the transport capacity concept, which has been shown to be deficient under certain conditions [Huang et al., 1999; Sander et al., 2007]. The H-R model treats erosion and deposition processes independ-

\footnotetext{
${ }^{1}$ Department of Geosciences, University of Arizona, Tucson, Arizona, USA.

${ }^{2}$ Department of Civil and Building Engineering, Loughborough University, Loughborough, UK.

${ }^{3}$ School of Geographical and Earth Sciences, University of Glasgow, Glasgow, UK

${ }^{4}$ Lancaster Environment Centre, Lancaster University, Lancaster, UK.
}

Copyright 2011 by the American Geophysical Union. 0043-1397/11/2010WR009375 ently, with the net outcome being the difference between these two process groups. It also models the development of a deposited layer that differs from the original soil in its cohesion and PSD. The feedback on erosion processes due to an evolving surface soil is thus accounted for; this allows us to model dynamical changes in erodibility and the PSD of the eroded soil.

[4] The H-R model has been applied with some success to various scenarios of soil erosion [e.g., Sander et al., 1996; Hairsine et al., 1999; Rose et al., 2003; Van Oost et al., 2004]. These applications, however, have been limited in various respects, e.g., using simplified approximations of the model, neglecting spatial or temporal variability, restricting to net erosion or net deposition conditions, and using either rainfall or runoff erosion processes. Moreover, the calibrated model parameters have not always been physically reasonable.

[5] Recently, Heng et al. [2009] presented a finite volume implementation of the full H-R model coupled with the Saint-Venant equations for overland flow. This allows us to model complex scenarios of soil erosion, where the processes of erosion by raindrop impact and surface runoff are concurrently active. We can also simulate the wetting up period, surface ponding, and the ensuing flow over nonuniform microtopography. In this paper, we apply the implementation to a series of detailed flume-scale experiments [Armstrong et al., 2010] to test the model's ability to reproduce the observed dynamics in terms of the PSD as well as the total concentration of sediment in the runoff. Brief descriptions of the model and the experimental study are presented in sections 2 and 3, respectively. We account for the topographical variation between experimental runs as well as the 
spatial heterogeneity per run by using photogrammetryderived surface measurements in the model in section 4 . Section 5 contains an in-depth discussion of the H-R model parameters (including the constraints) and our treatment of the preponding period. The results are presented in section 6 , with a discussion of the calibrated parameters and a sensitivity analysis. We conclude with a brief discussion of spatial resolution and scale in erosion prediction.

\section{Model Description}

[6] We use the Saint-Venant equations to describe overland flow:

$$
\begin{gathered}
\frac{\partial h}{\partial t}+\frac{\partial q}{\partial x}=P-f(t), \\
\frac{\partial q}{\partial t}+\frac{\partial}{\partial x}\left(\frac{q^{2}}{h}+\frac{1}{2} g h^{2}\right)=-g h\left(\frac{\mathrm{d} z}{\mathrm{~d} x}+S_{f}\right),
\end{gathered}
$$

where $h$ is the flow depth, $q$ is the unit discharge, $P$ is the rainfall intensity, $f(t)$ is the rate of infiltration, and $z$ is the bed elevation. The friction slope $S_{f}$ can be expressed as

$$
S_{f}=\frac{n^{2} q^{2}}{h^{10 / 3}},
$$

where $n$ is Manning's roughness coefficient.

[7] It may be argued that the Saint-Venant equations are not valid where the roughness is of the same order of magnitude as the flow depth. Nevertheless, they are an accepted approximation of overland flow [Zhang and Cundy, 1989; Tayfur et al., 1993; Esteves et al., 2000]. The specific form of the equations adopted in this work also assumes that slopes are gentle and that flow momentum is not significantly affected by infiltration. These simplifications are appropriate under most occurrences of shallow overland flow. The effect of rainfall on flow momentum is accounted for in Manning's $n$ (see section 5.1).

[8] Surface sealing is a common phenomenon with many soils under heavy rainfall (see Assouline [2004] for a review). It reduces the infiltration capacity of a soil, eventually leading to overland flow. Attempts have been made to model the physical process and the consequent effect on infiltration, but the parameters required can be onerous. We have adopted, as a first attempt, the simple Hortonian model

$$
f(t)=f_{c}+\left(f_{0}-f_{c}\right) \exp (-k t),
$$

where $f_{0}$ and $f_{c}$ are the initial and steady state infiltration capacities, respectively, and $k$ is a decay constant, as a phenomenological description of the process.

[9] The H-R equations governing soil erosion are

$$
\begin{gathered}
\frac{\partial h c_{i}}{\partial t}+\frac{\partial q c_{i}}{\partial x}=r_{i}+r_{r i}+e_{i}+e_{r i}-d_{i}, \\
\frac{\mathrm{d} m_{i}}{\mathrm{~d} t}=d_{i}-r_{r i}-e_{r i},
\end{gathered}
$$

where $c_{i}$ is the concentration in mass per unit volume and $m_{i}$ is the deposited mass per unit area of sediment in the $i$ th sediment class. The terms on the right-hand side of (3) and (4) are the rates of sediment entrainment (by surface runoff), reentrainment (of the deposited sediment), detachment (by raindrop impact), redetachment, and deposition, given by

$$
\begin{gathered}
r_{i}=(1-H) p_{i} \frac{\Omega_{e}}{J}, \\
r_{r i}=H \frac{m_{i}}{m_{T}} \frac{\Omega_{e}}{\frac{\rho_{s}-\rho_{w}}{\rho_{s}} g h}, \\
e_{i}=(1-H) p_{i} a P, \\
e_{r i}=H \frac{m_{i}}{m_{T}} a_{d} P, \\
d_{i}=\left[v_{i}+f(t)\right] c_{i},
\end{gathered}
$$

respectively. Here $H=\min \left(1, m_{T} / m_{T}^{*}\right)$, where $m_{T}=\sum m_{i}$ and $m_{T}^{*}$ is the mass of deposited (cohesionless) sediment required to shield the original cohesive soil from further erosion, $p_{i}$ is the fraction of class $i$ particles in the original soil, $\Omega_{e}\left(\mathrm{~W} \mathrm{~m}^{-2}\right)$ is the effective stream power, $J\left(\mathrm{~J} \mathrm{~kg}^{-1}\right)$ is the energy expended in entraining a unit mass of cohesive sediment, $\rho_{s}$ and $\rho_{w}$ are the densities of sediment and water, respectively, $a$ and $a_{d}\left(\mathrm{~kg} \mathrm{~m}^{-3}\right)$ are the detachabilities of the original soil and the deposited sediment, respectively, and $v_{i}\left(\mathrm{~m} \mathrm{~s}^{-1}\right)$ is the settling velocity of class $i$ sediment in still water. Implicit in (9) is the assumption that the suspended sediment is uniformly mixed in the water column.

[10] The system of equations (1)-(4) can be solved using the finite volume method [Heng et al., 2009]. We apply the model to a flume-scale experimental study described in section 3 .

\section{Experimental Study}

[11] The experimental study is detailed by Armstrong et al. [2010] but is summarized here for completeness. A $3.9 \mathrm{~m} \times 1.4 \mathrm{~m}$ flume was used in this study. To minimize boundary effects, the collection trough at the end of the flume was divided into three sections; surface runoff flowing into the two outer sections (each $0.15 \mathrm{~m}$ wide) was disregarded.

[12] The rainfall simulator is similar to that described by Strauss et al. [2000] and produces raindrops with a mean diameter of $2 \mathrm{~mm}$ that impact the soil surface at approximately $5.5 \mathrm{~m} \mathrm{~s}^{-1}$. The nozzles are opened and closed intermittently to regulate the rainfall intensity; the sampling period was designed to minimize biases due to this intermittency [Armstrong and Quinton, 2009]. While the mean rainfall intensity was fixed at $47 \mathrm{~mm} \mathrm{~h}^{-1}$ for this study, there was some spatial variation, particularly in the longitudinal direction (Figure 2), that can be attributed to the overlapping of nozzle spray areas. The numerical model allows us to specify the rainfall intensity in each finite volume cell, so we were able to take this spatial variation into account.

[13] Silt loam (4.6\% clay, $49.9 \%$ silt, and $45.5 \%$ sand) was placed and packed in the flume to various slope gradients $(3 \%, 6 \%$, and $9 \%)$, with triplicate runs (R1, R2, and R3) for each gradient. We determined the PSD of the silt loam and divided soil particles into 10 equal proportion size classes. 
Table 1. Class Representative Soil Particle Sizes and Corresponding Settling Velocities ${ }^{\mathrm{a}}$

\begin{tabular}{lcc}
\hline Class & Size $(\mu \mathrm{m})$ & $\begin{array}{c}\text { Settling Velocity } \\
\left(\times 10^{-3} \mathrm{~m} \mathrm{~s}^{-1}\right)\end{array}$ \\
\hline 1 & 2.9 & 0.0034 \\
2 & 5.6 & 0.013 \\
3 & 8.7 & 0.031 \\
4 & 13 & 0.065 \\
5 & 18 & 0.13 \\
6 & 26 & 0.27 \\
7 & 38 & 0.60 \\
8 & 59 & 1.4 \\
9 & 95 & 3.4 \\
10 & 170 & 9.6 \\
\hline
\end{tabular}

${ }^{\mathrm{a}}$ The soil fraction in each class is $10 \%$.

The class representative particle sizes and settling velocities (determined using Cheng's [1997] formula, assuming a sediment density of $2000 \mathrm{~kg} \mathrm{~m}^{-3}$ ) are shown in Table 1 .

\section{Photogrammetric Soil Surface Measurement}

[14] Stereoimages of the flume were captured before and after each run using two high-resolution digital cameras (Nikon D80, 10 MP) mounted above the flume. These were processed using Leica Photogrammetry Suite 9.0 to generate digital elevation models (DEMs) of the soil surface at $1 \mathrm{~cm}$ resolution. The DEMs revealed irregularities, such as depressions and confluences on the soil surfaces, as well as differences in topography between the experimental replicates for each slope gradient [Heng et al., 2010]. These small-scale topographic features and variations may partly account for the observed runoff and erosion responses. The numerical model allows us to test this hypothesis.

[15] To make use of the topographic data in the onedimensional numerical model, the following procedure was adopted.

[16] 1. Extract slope profiles from each DEM along three longitudinal transects spaced $0.3 \mathrm{~m}$ apart.

[17] 2. Average the slope profiles to obtain a one-dimensional approximation of the topography.

[18] 3. Downsample the data to $10 \mathrm{~cm}$ resolution.

[19] 4. Construct a cubic spline on the basis of the downsampled data.

[20] 5. Discretize the cubic spline at $2 \mathrm{~cm}$ resolution to obtain the input mesh for the model.

[21] Figure 1 compares the averaged DEM profile (after step 2) with the final model input mesh for run 1 on the $3 \%$ slope.

[22] This procedure essentially masks the grain- and aggregate-scale microtopography to satisfy the condition of a gradually varying flow (as assumed in the Saint-Venant equations). At the same time, sufficient detail is preserved at a practical resolution to allow differentiation between slopes (Figure 2).

\section{Model Application}

\subsection{Surface Runoff}

[23] The infiltration parameters $f_{0}, f_{c}$, and $k$ were calibrated for each run on the basis of the time to runoff, the shape of the discharge curve, and its asymptotic value. The

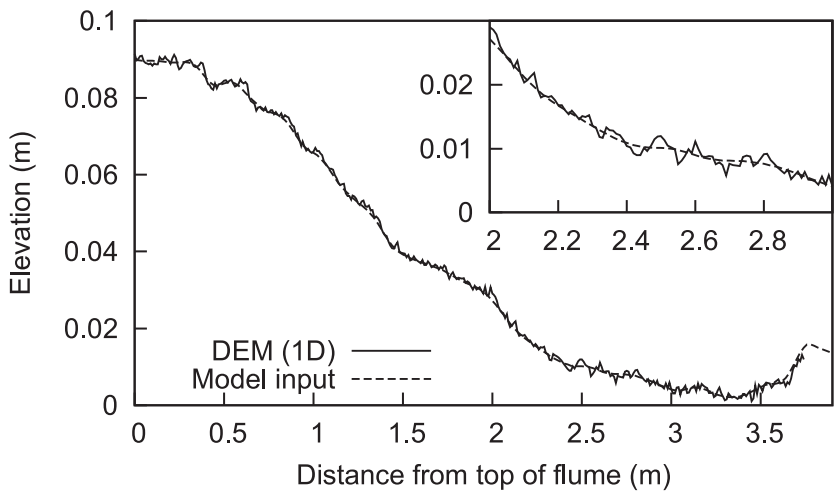

Figure 1. Comparing the model input topography with the digital elevation model (DEM) profile (averaged over three transects) for run 1 on the 3\% slope. An enlargement of one section of the slope is shown in the inset.

time to runoff (Table 2) is the time period between the start of rainfall and the collection of the first sample. Where there are significant depressions in the soil surface, the time to runoff can be much greater than the time to ponding, which occurs when $P=f(t)$. For overland flow, we assume $n=0.05$, after Engman [1986]. This friction coefficient includes the retarding effect of raindrop impact.

\subsection{Soil Erosion}

[24] The H-R model has a number of parameters that are difficult to measure accurately. Nonetheless, since every parameter has physical meaning, we may restrict the parameter space within reasonable bounds. Moreover, constraints may be derived that relate one parameter to another, effectively reducing the number of parameters.

[25] Soil detachment by raindrop impact is known to vary with flow depth [e.g., Mutchler and McGregor, 1983; Schultz et al., 1985; Torri et al., 1987; Proffitt et al.,

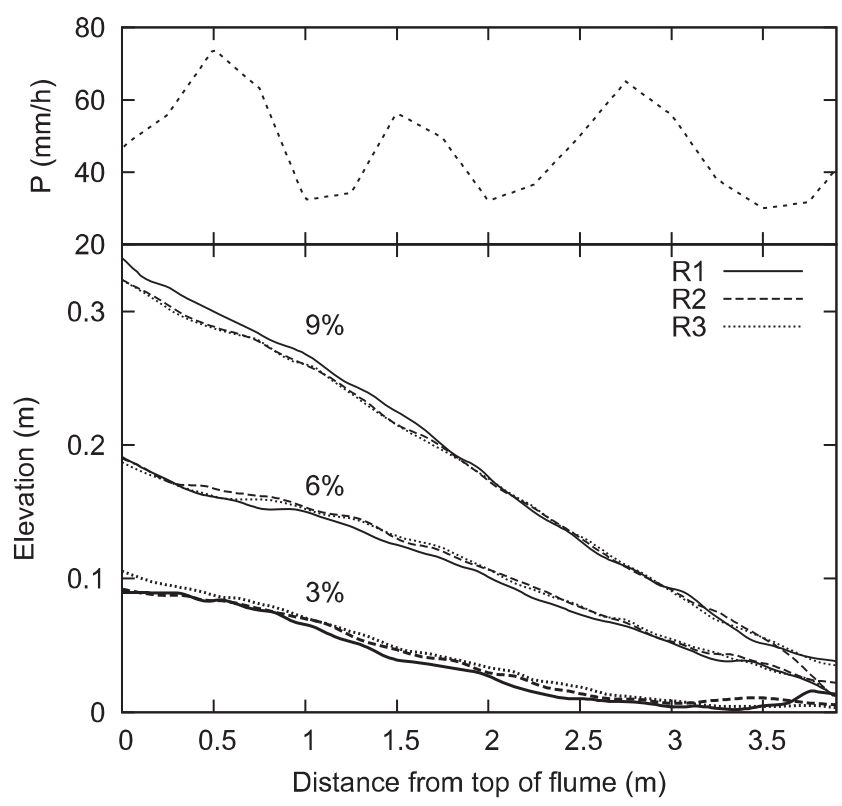

Figure 2. Rainfall and topographical inputs to the model. 
Table 2. Observed Times to Runoff

\begin{tabular}{ccc}
\hline Slope (\%) & Replicate & $\begin{array}{c}\text { Time to } \\
\text { Runoff (min) }\end{array}$ \\
\hline 3 & 1 & 14 \\
& 2 & 11 \\
6 & 3 & 4 \\
& 1 & 5 \\
9 & 2 & 4 \\
& 3 & 2 \\
& 1 & 6 \\
& 2 & 5 \\
\hline
\end{tabular}

1991]. Schultz et al. [1985] and Torri et al. [1987] showed that splash transport declined exponentially with the depth of ponding, becoming negligible for $h>2 \mathrm{~mm}$. On the other hand, Mutchler and McGregor [1983] and Proffitt et al. [1991] showed that soil loss in surface runoff continued to be significant up to $h=20 \mathrm{~mm}$. Clearly, sediment detachment and suspension due to raindrop-induced turbulence remain important in ponded water even as direct transport by raindrop splash becomes negligible.

[26] Mutchler and McGregor [1983] proposed an exponential relation between near-steady soil loss (SL, in $\mathrm{kg} \mathrm{h}^{-1}$ ) and $h$ :

$$
\mathrm{SL}=75.6 \exp (-0.29 h)+5.1\left(R^{2}=0.91\right) .
$$

[27] This makes SL (due to rainfall) tend to a nonzero value as $h \rightarrow \infty$, which is not reasonable. The power law suggested by Proffitt et al. [1991] seems more appropriate:

$$
\begin{gathered}
a=\left\{\begin{array}{cc}
a_{0}, & h \leq h_{0} \\
a_{0}\left(h_{0} / h\right)^{b}, & h>h_{0}
\end{array},\right. \\
a_{d}=\left\{\begin{array}{cc}
a_{d 0}, & h \leq h_{0} \\
a_{d 0}\left(h_{0} / h\right)^{b}, & h>h_{0}
\end{array},\right.
\end{gathered}
$$

where $a_{0}$ and $a_{d 0}$ are the detachabilities of cohesive and loose sediment, respectively, for flow depths below a threshold $h_{0}$, and $b$ is a positive constant. Since SL $=q c_{T}$, where $c_{T}$ is the total sediment concentration in the runoff and $c_{T} \propto a$ at steady state [Hairsine and Rose, 1991], a power law for $a$ implies the same for SL. The best fit power law for the data of Mutchler and McGregor [1983] is SL = $133.4 h^{-1.13}$, with $R^{2}=0.90$. In other words, for the silt loam used in their experiments, $b=1.13$. For comparison, Proffitt et al. [1991] found $b \approx 0.66$ for the two clayey soils in their study. We conveniently take $b=1$ for the silt loam in this study. Following Mutchler and Hansen [1970], we set $h_{0}=0.33 D_{R}$, where $D_{R}$ is the mean raindrop size, $2 \mathrm{~mm}$ in our case.

[28] Since the mass of deposited sediment required to shield the original soil decreases with decreasing rainfall erosivity, $m_{T}^{*}$ is implicitly a function of $h$. In fact, all else being equal, $m_{T}^{*} / a_{d}$ is a constant [Lisle et al., 1998]. Thus, analogously to $a_{d}$,

$$
m_{T}^{*}=\left\{\begin{array}{cc}
m_{T 0}^{*}, & h \leq h_{0} \\
m_{T 0}^{*}\left(h_{0} / h\right)^{b}, & h>h_{0}
\end{array} .\right.
$$

[29] Another way of looking at $a_{0}\left(\mathrm{~kg} \mathrm{~m}^{-3}\right)$ is that it is the ratio of the kinetic energy per unit rainfall $\left(\mathrm{J} \mathrm{m}^{-3}\right)$ to the energy required to detach a unit mass of the original soil $\left(\mathrm{J} \mathrm{kg}^{-1}\right)$. Thus, we can write

$$
J=\frac{0.5 \rho_{w} v_{R}^{2}}{a_{0}},
$$

where $v_{R}$ is the rainfall impact velocity. Given $v_{R}=5.5 \mathrm{~m} \mathrm{~s}^{-1}$, we have $J \approx 15,000 / a_{0}$ as another parametric constraint.

[30] Hairsine and Rose [1992a] originally formulated $\Omega_{e}$ as $F\left(\Omega-\Omega_{0}\right)$, where $\Omega=\rho_{w} g S_{f} q, \Omega_{0}$ is the threshold stream power below which there is no entrainment or reentrainment, and $F$ is the effective fraction of excess stream power. We can rewrite the original formulation as

$$
\Omega_{e}=\Omega-\Omega^{\prime \prime}-\Omega_{c}^{\prime}
$$

by making the substitutions $\Omega^{\prime \prime}=(1-F) \Omega$ and $\Omega_{c}^{\prime}=F \Omega_{0}$.

[31] $\Omega^{\prime \prime}$ can be thought of as the stream power expended on form roughness. Its form implies that form resistance increases with stream power or, equivalently for uniform flow, discharge. This is consistent with observations that form resistance increases with the Reynolds number [Rauws, 1988] or, perhaps more accurately, flow depth [Lawrence, 1997] as the form roughness elements are gradually inundated. A reasonable and parsimonious approximation would be to assume that $\widetilde{F}=1-F$ is constant, implying that $\Omega^{\prime \prime}$ varies linearly with $\Omega$.

[32] The last term in equation (13) is simply the critical stream power in connection with grain roughness alone [Abrahams et al., 1998; Ferguson, 2005], which we will denote as $\Omega_{c}^{\prime}$. With some algebraic manipulation, the formulation proposed by Abrahams et al. [1998] becomes

$$
\Omega_{c}^{\prime}=5.74 \rho_{w}\left(\theta_{c} D_{50} g R\right)^{3 / 2} \log \left(12.3 \frac{\theta_{c} R}{S_{0}}\right),
$$

where $\theta_{c}$ is the critical Shields parameter for incipient motion, $D_{50}$ is the median particle size, and $R=\left(\rho_{s}-\rho_{w}\right) /$ $\rho_{w}$. We note that the formulation of Ferguson [2005] is virtually identical, if we neglect relative size effects. For $\theta_{c}=0.045, \rho_{s}=2000 \mathrm{~kg} \mathrm{~m}^{-3}$, and $D_{50}=20 \mu \mathrm{m}$, the above formulation gives critical stream powers of $1.9 \times 10^{-4}$, $1.5 \times 10^{-4}$, and $1.2 \times 10^{-4} \mathrm{~W} \mathrm{~m}^{-2}$ for slopes of $3 \%, 6 \%$, and $9 \%$, respectively.

[33] The above rationalization reduces the number of independent parameters in the H-R model to four: $a_{0}, a_{d 0}$, $m_{T 0}^{*}$, and $\tilde{F}$. The detachability of the original soil $a_{0}$ may be sensitive to initial conditions that affect cohesion and soil strength [Le Bissonnais et al., 1995; Römkens et al., 2001; Mamedov et al., 2006] and so may vary between experimental runs. On the other hand, we may assume $a_{d 0}$ to be a constant for the soil used in this study. Obviously, $a_{d 0} \geq a_{0}$ is a parametric constraint. Furthermore, we deduce from Abrahams and Parsons [1994] that $\tilde{F}$ is larger than 0.9.

[34] On the basis of bulk density measurements [Armstrong et al., 2010], a $1 \mathrm{~mm}$ thick layer of deposited sediment has a mass of approximately $1.4 \mathrm{~kg} \mathrm{~m}^{-2}$. The deposited layer required to shield the original soil completely cannot be much thinner than that. Thus, a physically reasonable lower bound for $m_{T 0}^{*}$ is $1 \mathrm{~kg} \mathrm{~m}^{-2}$. 
[35] The four independent parameters were calibrated to fit the experimental data in terms of PSD as well as total sediment concentration. Given the computational cost of solving the model, calibration was performed manually, with the goodness of fit evaluated visually. The effect of uncertainties in the parametric constraints and assumptions are examined in section 6.5 .

\subsection{Initial and Boundary Conditions}

[36] We used the same initial conditions for all model runs: $h=0, q=0$, and $m_{i}=0$. The periods before ponding were explicitly modeled. Sediment detached by raindrop impact in the preponding period is not transported off-site (assuming that the net sediment transport due to rain splash is negligible on gentle slopes), so there is a buildup of loose sediment on the soil surface. Since $a_{d}$ is typically much larger than $a$, the presence of predetached sediment on the soil surface results in a more rapid initial rise in suspended sediment concentration as well as a higher peak concentration than would otherwise be the case. It is important therefore to model this buildup of loose sediment prior to runoff generation.

[37] We observe that the left side of equation (3) is zero before ponding, so $d_{i}-e_{r i}=e_{i}$. Substituting this into equation (4) and summing over all $i$, we then get $\mathrm{d} m_{T} / \mathrm{d} t=$ $\Sigma e_{i}=(1-H) a P$. Given $m_{T}=0$ at $t=0$, the solution of the differential equation is

$$
m_{T}(t)=m_{T}^{*}\left[1-\exp \left(-\frac{a P}{m_{T}^{*}} t\right)\right] .
$$

[38] Thus, the mass of loose sediment on the soil surface approaches the critical mass required to shield the original soil completely, and the rate at which $m_{T}^{*}$ is approached increases with the ratio of $a P$ to $m_{T}^{*}$. Because of the spatially varying topography, we model this process numerically. This is achieved by setting $h c_{i}=0$ and incrementing $m_{i}$ by $(1-H) p_{i} a P \Delta t$ at each time step until $h \geq h_{p}$, where $h_{p}$ is a small artificial threshold to distinguish between ponding and nonponding in the numerical model [Heng et al., 2009].

[39] The boundary conditions are a reflective (zero flux) boundary at the top of the slope and a transmissive one at the bottom.

\subsection{Time Steps}

[40] The allowable time step for the numerical solution tends to be governed by the condition [Heng et al., 2009]

$$
\Delta t \leq \frac{h_{\min }}{v_{I}+f(t)},
$$

where $v_{I}$ is the settling velocity of the largest particles. This severely restricts the time step since $h \rightarrow 0$ at the top of the slope (where there is no inflow). We may relax this constraint by reasoning that only particles smaller than $h$ can logically be suspended in the surface runoff. The preponding process described in section 5.3 continues to apply for larger particles until $h>D$, the size of the particles. The criterion then becomes

$$
\Delta t \leq \min _{k}\left[\frac{h_{k}}{v_{j, k}+f(t)}\right],
$$

where $h_{k}$ is the flow depth in the $k$ th cell and $v_{j, k}$ is the settling velocity of the $j$ th sediment class such that $D_{j}<h_{k}<$ $D_{j+1}$. This modification of the criterion for the allowable time step improves computational efficiency by an order of magnitude.

\section{Model Output}

[41] The best fit model parameters are shown in Table 3, and the model output is plotted against the observed data in Figure 3.

\subsection{Surface Runoff}

[42] The model generally reproduces the measured discharge well, although discrepancies can be observed. For $\mathrm{R} 1$ on the 3\% slope, the one-dimensional model predicts a rapid initial rise in discharge associated with the overflow of the depression at the end of the slope. On the actual twodimensional surface, the overflow could have been incremental, resulting in a more gradual rise.

[43] For R1 on the $9 \%$ slope, the modeled discharge curve matched the early and late time data well, but it was significantly higher for $8 \geq t \geq 60 \mathrm{~min}$. The first plateau in the measured discharge suggests that the initial source area was small. The filling up of depression storage on the surface resulted in increased connectivity and hence a larger source area (corresponding to the final plateau). The sequence of images shown in Figure 4 lends support to this conjecture.

[44] In R2 and R3 on the 9\% slope, the measured discharge at steady state (or that suggested by the trend) exceeded the theoretical maximum based on a $3.9 \mathrm{~m} \times 1.1 \mathrm{~m}$ source area and zero infiltration. The photogrammetric measurements [Heng et al., 2010] indicate that rainfall on the exclusion zones on either side of the flume (designed to eliminate boundary effects) very likely flowed into the

\begin{tabular}{|c|c|c|c|c|c|c|c|c|}
\hline Slope (\%) & Replicate & $f_{0}\left(\mathrm{~mm} \mathrm{~h}^{-1}\right)$ & $f_{c}\left(\mathrm{~mm} \mathrm{~h}^{-1}\right)$ & $k\left(\times 10^{-3} \mathrm{~s}^{-1}\right)$ & $a_{0}\left(\mathrm{~kg} \mathrm{~m}^{-3}\right)$ & $a_{d 0}\left(\mathrm{~kg} \mathrm{~m}^{-3}\right)$ & $m_{T 0}^{*}\left(\mathrm{~kg} \mathrm{~m}^{-2}\right)$ & $\widetilde{F}(\%)$ \\
\hline \multirow[t]{3}{*}{3} & 1 & 45 & 13 & 0.80 & 17 & 1900 & 1.5 & 98.0 \\
\hline & 2 & 75 & 0 & 0.55 & 11 & 1900 & 3.0 & 98.0 \\
\hline & 3 & 49 & 7 & 0.75 & 21 & 1900 & 2.2 & 98.0 \\
\hline \multirow[t]{3}{*}{6} & 1 & 39 & 4 & 0.71 & 10 & 1900 & 2.5 & 98.0 \\
\hline & 2 & 49 & 17 & 0.94 & 10 & 1900 & 2.0 & 98.5 \\
\hline & 3 & 46 & 0 & 0.93 & 11 & 1900 & 2.5 & 98.5 \\
\hline \multirow[t]{3}{*}{9} & 1 & 61 & 6 & 0.69 & 9 & 1900 & 3.0 & 99.0 \\
\hline & 2 & 52 & 0 & 0.50 & 10 & 1900 & 4.0 & 99.0 \\
\hline & 3 & 45 & 0 & 1.00 & 27 & 1900 & 5.0 & 98.0 \\
\hline
\end{tabular}
main central zone, effectively increasing the source area.

Table 3. Calibrated Model Parameters 

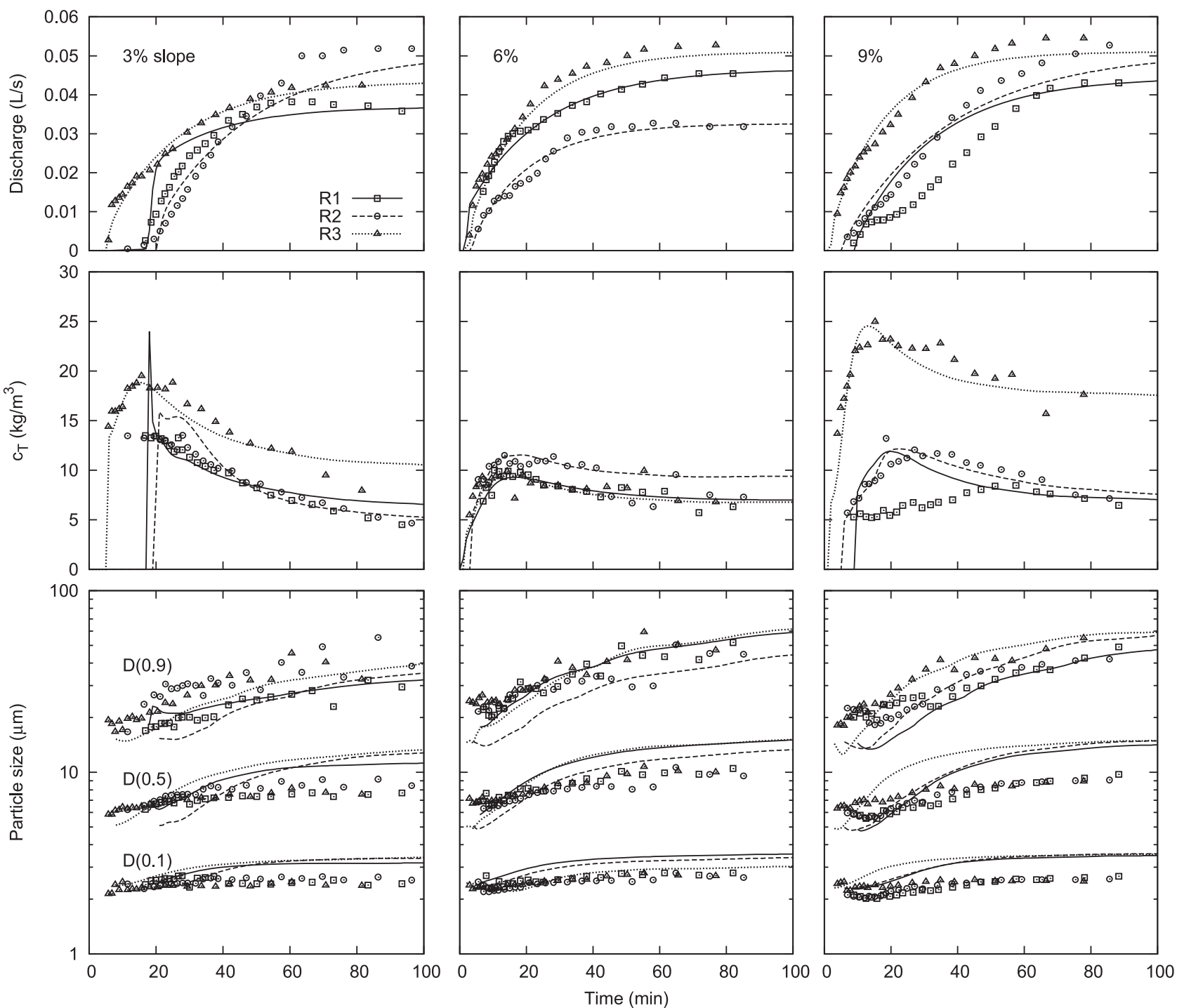

Figure 3. Model output (lines) versus observed data (points) for discharge, total suspended sediment concentration, and particle size distribution (PSD) evolution on the (a) 3\%, (b) 6\%, and (c) $9 \%$ slopes. $\mathrm{D}(0.9), \mathrm{D}(0.5)$, and $\mathrm{D}(0.1)$ denote the $90 \mathrm{th}, 50 \mathrm{th}$, and 10th percentile particle sizes, respectively.
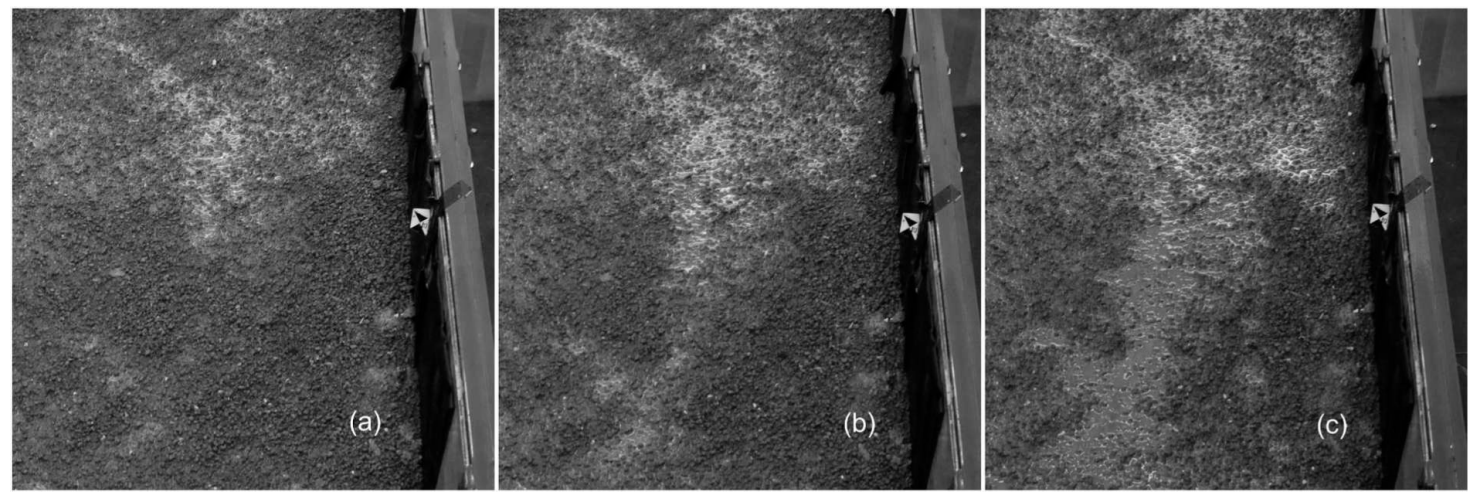

Figure 4. Images captured during replicate 1 on the $9 \%$ slope at approximately (a) $10 \mathrm{~min}$, (b) $20 \mathrm{~min}$, and (c) 50 min after the start of rainfall, showing an increase in runoff connectivity as storage areas filled up. 
[45] The one-dimensional model cannot properly account for the effects highlighted in the above discussion. Nonetheless, it is a valid first approximation insofar as the transverse flow component is an order of magnitude less significant than the longitudinal. The calibrated infiltration parameters (Table 3) reflect experimental variabilities such as the antecedent moisture content, the rate of surface sealing, and the characteristics of the surface seal.

\subsection{Soil Erosion}

[46] The magnitude and timing of the peaks in sediment concentration as well as the subsequent declines are well reproduced by the model. The only significant discrepancy appears for R1 on the $9 \%$ slope: the observed behavior is atypical and appears to be related to the irregularity in the discharge (highlighted in section 6.1).

[47] The model also reproduced the PSD of the sediment in the runoff and the coarsening trends through time. The general pattern is one of relatively rapid coarsening near the beginning of the erosion event, with a gradual decline in the rate of change as the system approaches steady state (Figure 3). The continuing upward trend in particle sizes toward the end of the experiments (predicted as well as observed) indicates that steady state had not been reached.

[48] Although the model accurately predicted the 90th percentile particle size (denoted by $\mathrm{D}(0.9)$ in Figure 3 ) and its evolution through time, model predictions for the median and 10th percentile particle sizes, denoted by $\mathrm{D}(0.5)$ and $\mathrm{D}(0.1)$, respectively, start to deviate from the observed values at $20-30 \mathrm{~min}$ after the start of rainfall. On average, the predicted $\mathrm{D}(0.5)$ and $\mathrm{D}(0.1)$ are $46 \%$ and $28 \%$ larger than the values observed toward the end of the experiments, respectively. This means there were higher proportions of fine particles in the runoff than predicted. This may be due in part to the breakdown of aggregates, which effectively changed the PSD of the soil being eroded. Thus, the observed $\mathrm{D}(0.5)$ and $\mathrm{D}(0.1)$ seem to approach steady state values that are smaller than predicted by the model.

[49] Difficulties in sampling may also account for the particle size discrepancies. The analysis of particle sizes by laser diffraction necessitated taking small subsamples from each sample [Armstrong et al., 2010]. Although care was taken to mix each sample thoroughly before taking subsamples, the subsamples may still be biased toward finer particles, as sand-size particles dropped out of suspension very quickly. This systematic bias is not constant across samples but becomes more pronounced with the coarsening of the sediment in the runoff; this may explain why differences between the predicted and observed $\mathrm{D}(0.5)$ and $\mathrm{D}(0.1)$ were larger toward the end than at the beginning of the experiments.

[50] In view of these uncertainties, the "errors" may not be fatal to the model's potential for predicting sediment and nutrient export. Further work would be necessary to identify the reasons and impact of this underprediction of fines content on water quality modeling.

\subsection{Spatial Variations}

[51] As an instance of the spatial variations in sediment concentration and the deposited sediment mass, the model output for $\mathrm{R} 1$ on the $6 \%$ slope at $t=100 \mathrm{~min}$ is shown in Figure 5. Comparing this with the microtopography of the slope shown in Figure 2, one can observe that the drops in $c_{T}$ (and corresponding jumps in $m_{T}$ ) occur where the local gradient is gentle because of the relatively large flow depths (and hence small $a, a_{d}$, and $\Omega$ ). There is also a fining of the suspended sediment in these regions due to the rapid deposition of large particles. This can be observed in Figure 5 (bottom); MWD $=\Sigma c_{i} D_{i} / c_{T}$ is the mean weight diameter of the sediment. A corresponding drop in the MWD of the deposited sediment is also evident.

[52] The spatial variations highlight the potential use of distributed measurements in the development, validation, and calibration of a soil erosion model [Jetten et al., 2003]. Such measurements are difficult to obtain during an erosion event. Instead, Figure 5 suggests that a distributed sampling and analysis of the surface layer after an erosion event may yield important data for comparison with the model output. A visual inspection of the surface after the event does lend some support to the model's prediction that the deposited layer is finer in local depressions, but a more detailed study is needed to obtain quantitative data.

\subsection{Parametric Analysis}

[53] The model predictions are meaningless without a consistent set of parameters. The calibrated H-R model parameters (mean \pm 1 standard deviation) are $a_{0}=140 \pm$ $6.3 \mathrm{~kg} \mathrm{~m}^{-3}, a_{d 0}=1900 \mathrm{~kg} \mathrm{~m}^{-3}, m_{T 0}^{*}=2.9 \pm 1.1 \mathrm{~kg} \mathrm{~m}^{-\overline{2}}$, and $=98.3 \pm 0.4 \%$.

[54] The detachability parameters $a_{0}$ and $a_{d 0}$ can be related to the interrill erodibility constant $K_{\mathrm{IR}}\left(\mathrm{kg} \mathrm{s} \mathrm{m}^{-4}\right)$ used in the Water Erosion Prediction Project (WEPP) erosion model. Interrill sediment delivery (in terms of sediment mass per unit area per unit time) is described in the WEPP model by $D_{\mathrm{IR}}=f_{S} K_{\mathrm{IR}} P \sigma_{\mathrm{IR}}$, where $f_{s}=1.05-0.85$

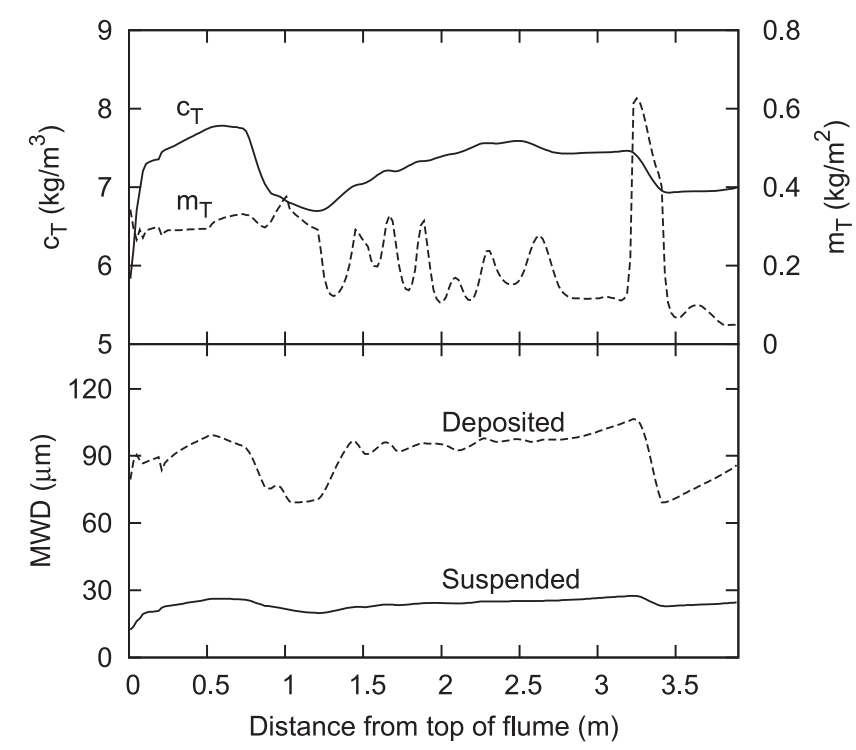

Figure 5. Spatial variation of the suspended and deposited sediment (from model simulations) for R1 on the $6 \%$ slope at $t=100 \mathrm{~min}$. Here $c_{T}$ is the total suspended sediment concentration, $m_{T}$ is the total deposited mass per unit area, and MWD is the mean weight diameter of the deposited or suspended sediment. 
$\exp \left[-4 \sin \left(\arctan S_{0}\right)\right]$ is a slope factor and $\sigma_{\mathrm{IR}}\left(\mathrm{m} \mathrm{s}^{-1}\right)$ is the interrill runoff rate [Flanagan and Nearing, 1995]. Suppose rills are spaced $L_{R}$ apart; the unit discharge into each rill is then $q_{\mathrm{IR}}=\sigma_{\mathrm{IR}} L_{R}$. If the sediment concentration in the discharge is $c_{T}$, then $D_{\mathrm{IR}}=q_{\mathrm{IR}} c_{T} / L_{R}=\sigma_{\mathrm{IR}} c_{T}$. The H$\mathrm{R}$ solution for $c_{T}$ at steady state, for $h \leq h_{0}$, is [Tromp-van Meerveld et al., 2008]

$$
c_{T}=\frac{a_{0} P}{P-f_{c}+\left(\bar{v}+f_{c}\right) \frac{a_{0}}{a_{d 0}}},
$$

where $\bar{v}=\Sigma p_{i} v_{i}$ is the weighted mean settling velocity. Equating the two definitions for $D_{\mathrm{IR}}$, we get

$$
\frac{1}{f_{S} K_{\mathrm{IR}}}=\frac{P-f_{c}}{a_{0}}+\frac{\bar{v}+f_{c}}{a_{d 0}} .
$$

[55] Substituting $a_{0}=14 \mathrm{~kg} \mathrm{~m}^{-3}, a_{d 0}=1900 \mathrm{~kg} \mathrm{~m}^{-3}$, $f_{c}=5.2 \mathrm{~mm} \mathrm{~h}^{-1}$ (mean value), $\bar{v}=1.6 \mathrm{~mm} \mathrm{~s}^{-1}$, and $S_{0}=$ $6 \%$ into (15), we get $K_{\mathrm{IR}}=1.57 \times 10^{6} \mathrm{~kg} \mathrm{~s} \mathrm{~m}^{-4}$. This is close to the erodibility constant of $1.45 \times 10^{6} \mathrm{~kg} \mathrm{~s} \mathrm{~m}^{-4}$ determined experimentally for the Caribou soil (which is of a similar texture to ours) in the WEPP database [Elliot et al., 1989]. Thus, the detachability values obtained in this study appear to be consistent with independently obtained data.

[56] The presence of $P$ and $f_{c}$ in (15) implies either (1) $K_{\mathrm{IR}}$ is a complex function of $P$ and $f_{c}$, if $a_{0}$ and $a_{d 0}$ are constants, or (2) $a_{0}$ and $a_{d 0}$ are not constants, if $K_{\text {IR }}$ is a soil property. Supposing the latter to be true, (15) shows that $a_{d 0}$ can effectively be assumed constant for a given soil (one of our assumptions in calibrating the model) since $f_{c}$ is generally much smaller than $\bar{v}$ ( 3 orders of magnitude in our case).

[57] It is probable that all three erodibility "constants" are dependent on event size. If so, the assumption that they are invariant would result in prediction errors when the event is much larger or smaller than that for which the parameters were calibrated. In practice, we may calibrate a model on the basis of the more frequent medium-intensity events and expect to get acceptable predictions in most scenarios.

[58] The $m_{T 0}^{*}$ values (i.e., the deposited sediment mass required for complete shielding when $h \leq h_{0}$ ) obtained in this study are physically realistic but appear to be much larger (1-2 two orders of magnitude) than those obtained in previous applications of the model [e.g., Sander et al., 1996; Rose et al., 2007; Tromp-van Meerveld et al., 2008]. Part of the discrepancy can be attributed to the assumption in previous studies that $m_{T}^{*}$ is independent of $h$. In other words, the effect of flow depth was incorporated in the calibrated $m_{T}^{*}$. Given the flow depths were an order of magnitude larger than $h_{0}$, we can deduce from (12) that the corresponding $m_{T 0}^{*}$ are an order of magnitude larger than the calibrated $m_{T}^{*}$. Thus, the $m_{T 0}^{*}$ values obtained in this study are consistent with the higher end values obtained in previous studies. The less realistic lower-end values in previous studies may be due to the various assumptions made (e.g., constant excess rainfall and steady flow) to simplify the governing equations for analytical solution.

[59] There is some variability in $m_{T 0}^{*}$ between runs. In agreement with the results of Walker et al. [2007], there appears to be an inverse relationship between $m_{T 0}^{*}$ and the

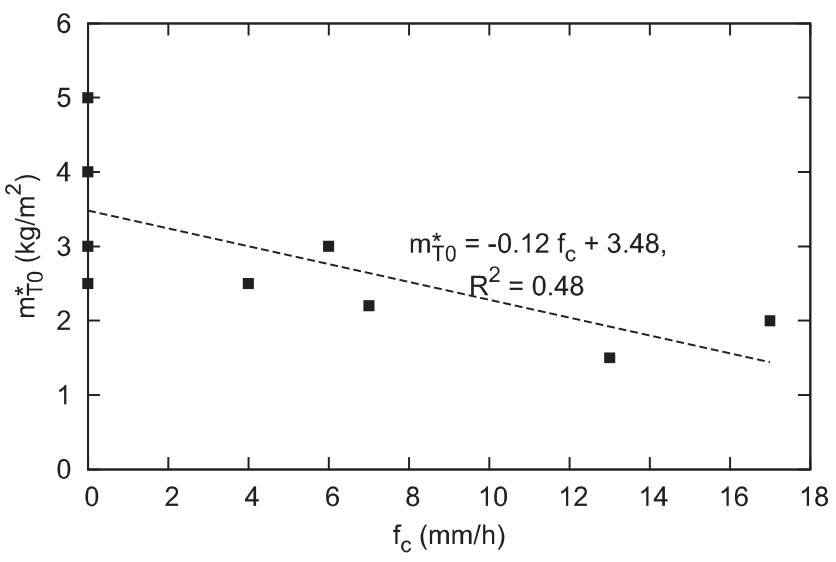

Figure 6. Variation of $m_{T 0}^{*}$ (the deposited sediment mass per unit area required to shield the underlying soil completely) with $f_{c}$ (the steady state infiltration capacity).

rate of infiltration (Figure 6). Since infiltration changes with time, $m_{T 0}^{*}$ is strictly not even constant for each run. Ideally, $m_{T}^{*}$ should be defined as a function of $f(t)$ and $h$; this one function can then be used for all runs. There is, however, a paucity of data on which to base this function. We have conducted additional experiments to investigate this dependence and will be discussing the results in a forthcoming paper.

[60] Finally, the calibrated values of $\tilde{F}$ indicate that a large proportion of total stream power is expended on form resistance, in agreement with Abrahams and Parsons [1994]. There is a weak increasing trend with slope, possibly due to decreasing flow depths and hence relative submergence of roughness elements.

\subsection{Sensitivity Analysis}

[61] To better understand the behavior of the model, we performed a series of tests with R1 on the $6 \%$ slope as the baseline.

[62] In relating rainfall detachment to flow depth by (10) and (11), we had assumed, on the basis of previous studies, that $b=1$ and $h_{0}=0.7 \mathrm{~mm}$. Figure 7 a shows that the model is relatively insensitive to $b$. However, $c_{T}$ drops considerably with a smaller $h_{0}$, the effect becoming more pronounced with distance downslope (Figure 8a), as $h / h_{0}$ increases. The form of the power laws (10) and (11) implies that the effect of reducing $h_{0}$ by a factor $\chi$ can be offset by correspondingly increasing $a_{0}$ and $a_{d 0}$ by a factor $\chi^{b}$. The PSD of the eroded sediment, in terms of the MWD, is insensitive to $b$ and $h_{0}$ (Figure 7a).

[63] The detachability of the original soil $a_{0}$ has a significant impact on the mean and steady state sediment concentrations (also evident from (14)), but its effect on the PSD of the sediment is negligible (Figure 7b). On the other hand, increasing/decreasing $\tilde{F}$ (i.e., decreasing/increasing the proportion of total stream power acting on the sediment) significantly decreases/increases the rate of coarsening of the eroded sediment (the rate of approach to steady state), with relatively little impact on the steady state sediment concentration.

[64] As with $\tilde{F}$, increasing/decreasing $a_{d 0}$ (the detachability of loose sediment) increases/attenuates the peak sediment concentration and increases/decreases the sediment 

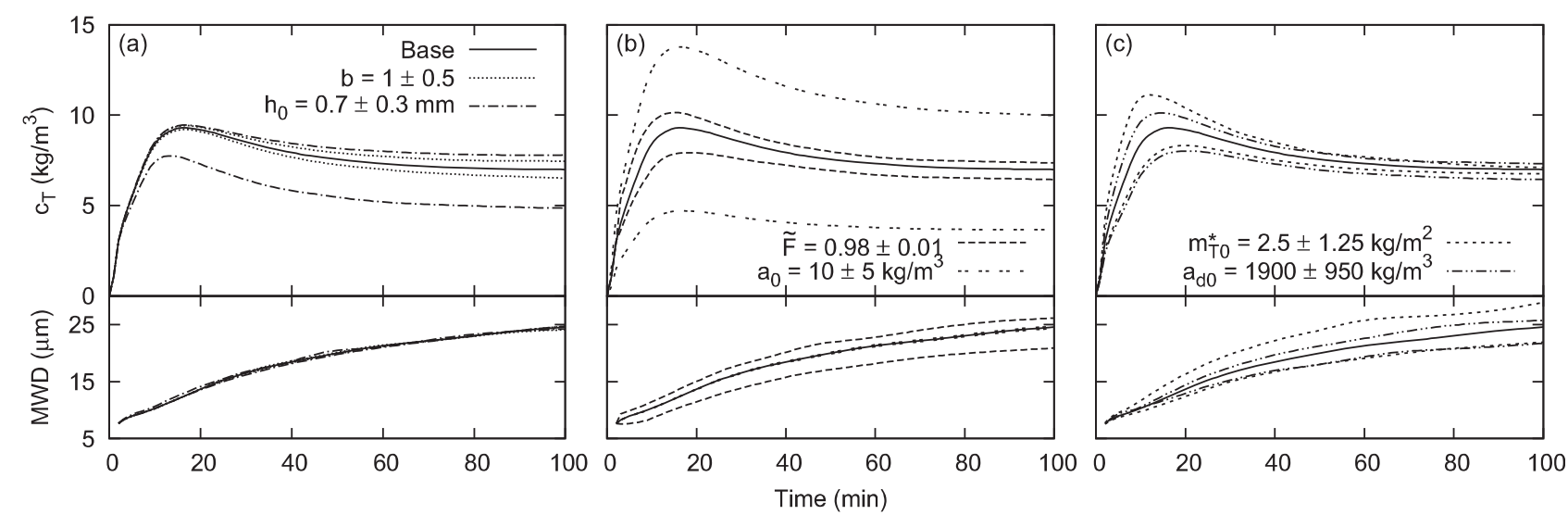

Figure 7. Sensitivity of the model output in terms of $c_{T}$ and the MWD of the suspended sediment at $x$ $=L$, with (a) varying $b$ and $h_{0}$, (b) varying $\tilde{F}$ and $a_{0}$, and (c) varying $m_{T 0}^{*}$ and $a_{d 0}$. See text for further explanation.

turnover rate so that it takes a shorter/longer time to reach steady state (Figure $7 \mathrm{c}$ ). The converse is true for $m_{T 0}^{*}$ (the deposited sediment mass required for complete shielding).

[65] The effect of parametric uncertainties on $m_{T}$ is most pronounced in local depressions (Figure 8; see Figure 2 for the microtopography), which act as sediment traps.

[66] The above sensitivity analysis illustrates how the $\mathrm{H}-\mathrm{R}$ parameters may be calibrated. We can more or less determine $a_{0}$ on the basis of the steady state $c_{T}$, which is insensitive to the other parameters. It is harder to determine $\tilde{F}, a_{d 0}$, and $m_{T 0}^{*}$ because they produce similar effects on model output at $x=L$. It helps to have multiple data sets from experiments under different conditions (as in this study) and to impose parametric constraints (such as $a_{d 0}$ is constant for all runs). Distributed data may also help to separate out the effects of the three parameters, as Figure 8 demonstrates. In lieu of this, the a posteriori check against an independent measure of erodibility (section 6.4) lends credibility to the calibrated values for $a_{0}$ and $a_{d 0}$.

\section{Discussion and Conclusions}

[67] We have presented in this paper an application of the full H-R model to a detailed flume-scale experimental study. The numerical implementation of the model coupled with the Saint-Venant equations allows us to model soil erosion on complex topography and with realistic initial conditions. The model output matches fairly closely the observed data, including the dynamic evolution of the eroded sediment's PSD, which is requisite to predicting accurately the fluxes of nutrients sorbed onto the sediment. Importantly, the calibrated parameters are consistent with independent data in the literature, which is important if this is not to become a mere curve-fitting exercise.

[68] While the model represents faithfully the processes of soil erosion, the question inevitably arises as to its applicability in the field and at larger scales, where data on soil PSD, topography, etc., would be much sparser. Figures 9 and 10 show the effect of using a uniform averaged slope
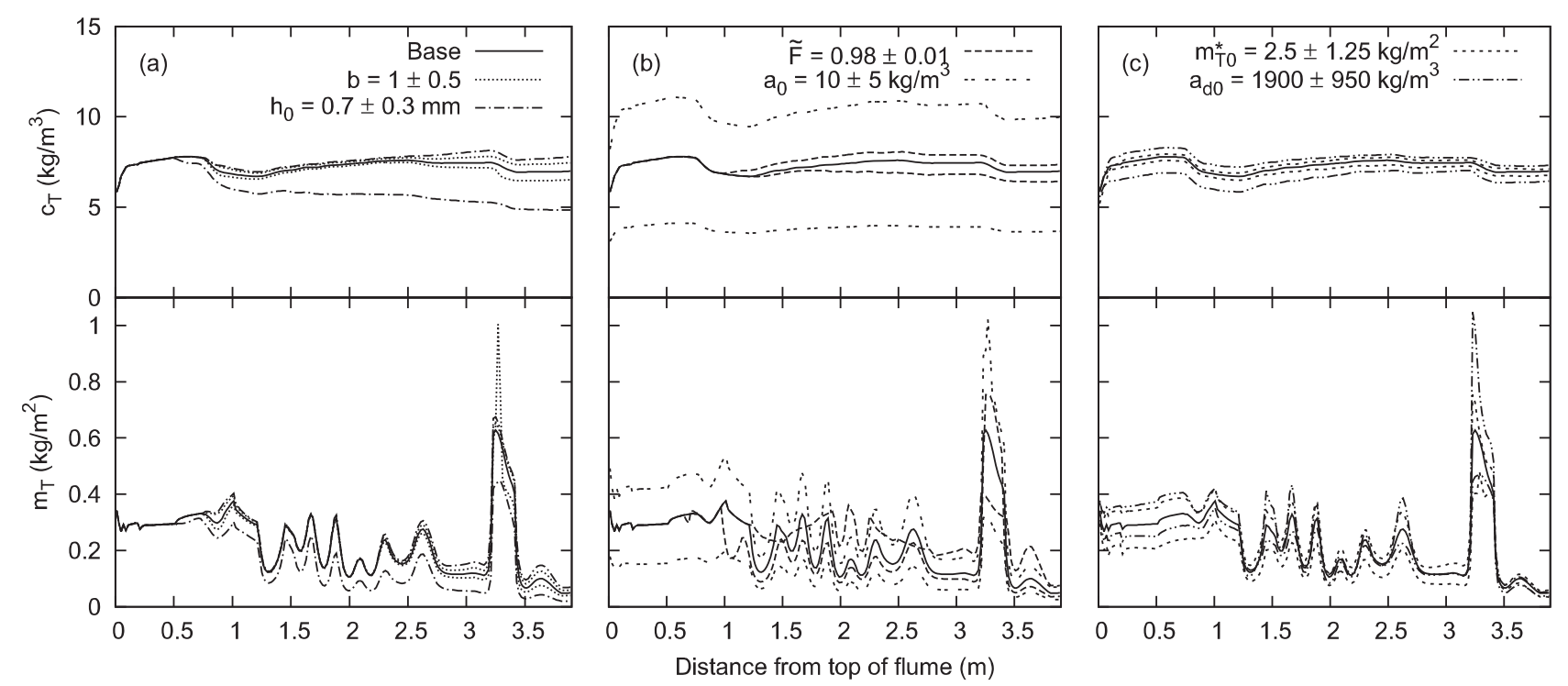

Figure 8. Sensitivity of the model output in terms of $c_{T}$ and $m_{T}$ at $t=100 \mathrm{~min}$, with (a) varying $b$ and $h_{0}$, (b) varying $\tilde{F}$ and $a_{0}$, and (c) varying $m_{T 0}^{*}$ and $a_{d 0}$. See text for further explanation. 


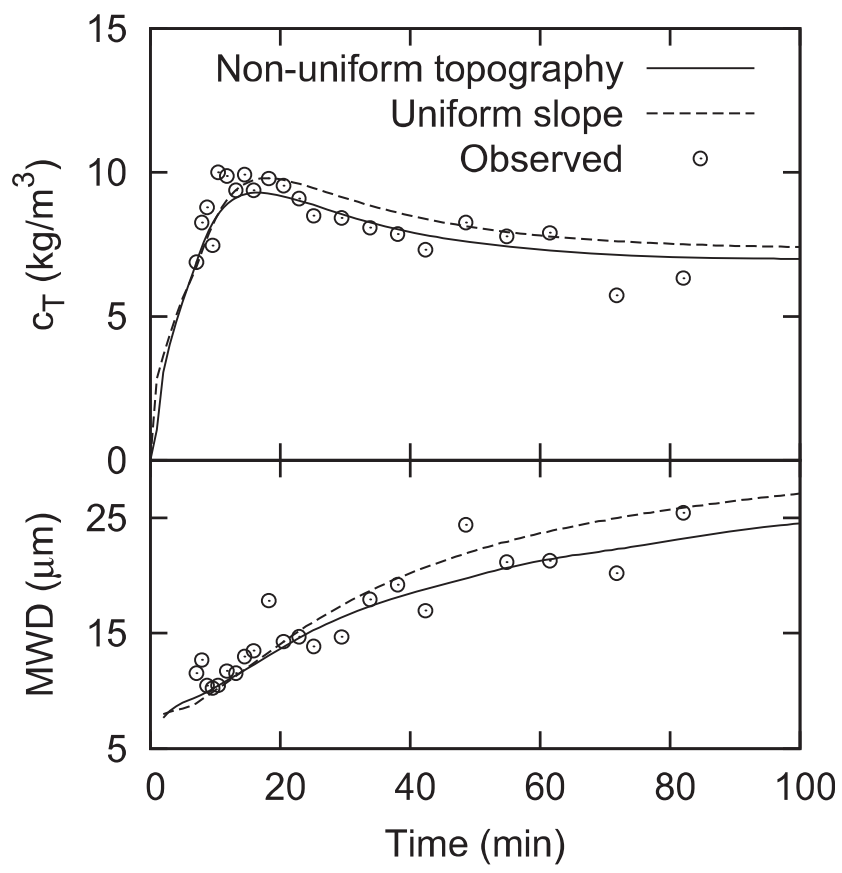

Figure 9. Effect of assuming a uniform slope on the modeled sediment concentration $c_{T}$ and the sediment MWD at $x=L$ for R 1 on the $6 \%$ slope. The same model parameters calibrated with respect to the nonuniform topography were used for the uniform slope simulation. The observed experimental data are also plotted for comparison.

to represent the $6 \% \mathrm{R} 1$ slope in conjunction with model parameters that were calibrated with respect to the nonuniform topography. The total sediment yield predicted on the basis of the uniform slope is $6.3 \%$ greater than that based on the varying topography. The corresponding increase in the MWD of the eroded sediment (Figure 9) suggests that the increase in sediment yield is due to a greater amount of coarse sediment in the runoff. Figure 10 shows that the uniform slope approximation results in an underprediction of the deposited sediment mass, particularly in areas of depression. It is thus evident that a larger number of coarse particles is transported out of the eroding area (instead of being trapped in depressions) when the slope is assumed to be uniform.

[69] In essence, this is a scale issue that has been explored by others [Jetten et al., 2003; Rojas et al., 2008] at larger scales. It seems clear that erosion parameters calibrated at one spatial resolution will produce poorer predictions at a different spatial resolution. The general lack of data at the temporal and spatial resolutions necessary for physics-based erosion prediction continues to hamper progress in this direction (although LIDAR and other remote sensing technologies show promise as possible solutions). Nonetheless, inasmuch as a scale-independent model must account for "those erosion products that are entrained as sediment load but are redeposited" [Osterkamp and Toy, 1997, p. 155], the H-R model is a step in the right direction. A necessary step forward would be to apply this model at field and catchment scales, which should yield some interesting results as well as raise further research questions.

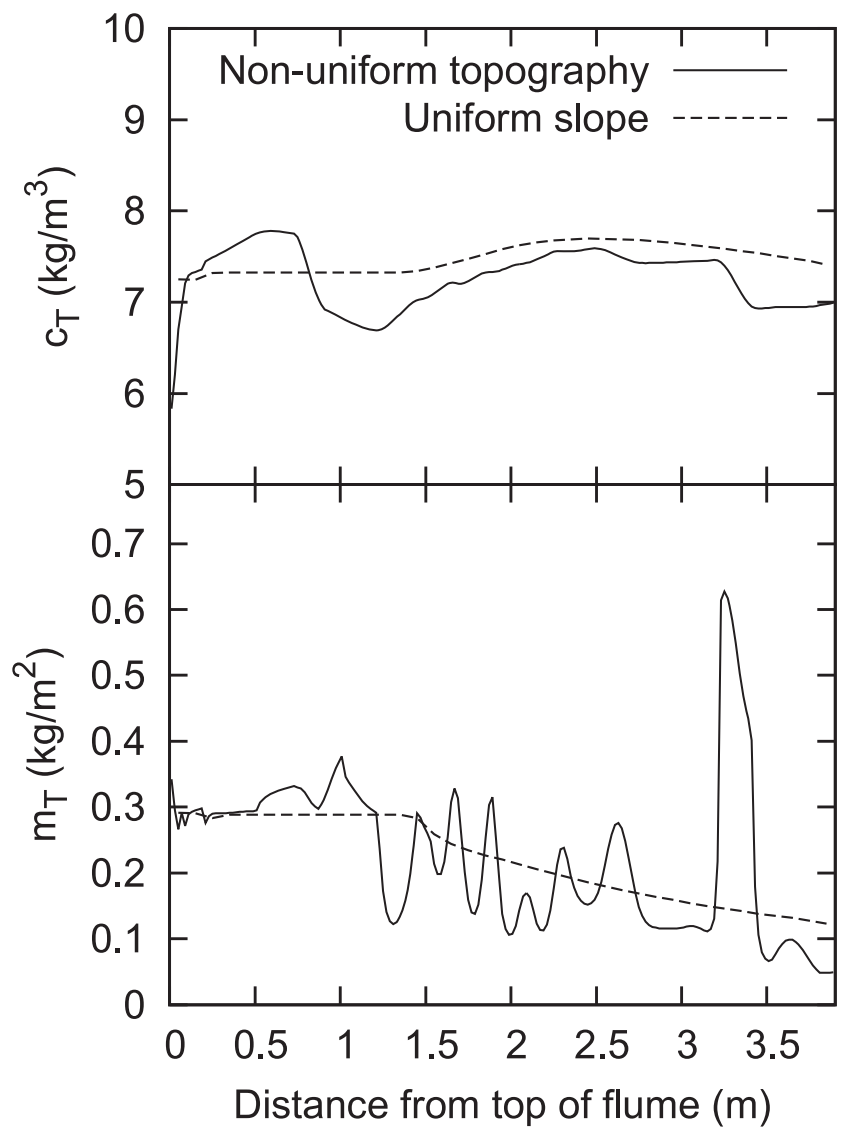

Figure 10. Effect of assuming a uniform slope on the modeled sediment concentration $c_{T}$ and the deposited sediment mass $m_{T}$ at $t=100 \mathrm{~min}$ for $\mathrm{R} 1$ on the $6 \%$ slope. The same model parameters calibrated with respect to the nonuniform topography were used for the uniform slope simulation.

[70] Acknowledgment. This work was supported by the Natural Environment Research Council, United Kingdom, under grant NE/E007015/1.

\section{References}

Abrahams, A., and A. Parsons (1994), Hydraulics of interrill overland flow on stone-covered desert surfaces, Catena, 23(1-2), 111-140, doi:10.1016/ 0341-8162(94)90057-4.

Abrahams, A. D., G. Li, C. Krishnan, and J. F. Atkinson (1998), Predicting sediment transport by interrill overland flow on rough surfaces, Earth Surf. Processes Landforms, 23(12), 1087-1099, doi:10.1002/(SICI) 1096-9837(199812)23:12\%3C1087::AID-ESP934\%3E3.0.CO;2-4.

Armstrong, A., and J. N. Quinton (2009), Pumped rainfall simulators: The impact of rain pulses on sediment concentration and size, Earth Surf. Processes Landforms, 34, 1310-1314, doi:10.1002/esp.1810.

Armstrong, A., J. N. Quinton, B. C. P. Heng, and J. H. Chandler (2010), Variability of interrill erosion at low slopes, Earth Surf. Processes Landforms, 36(1), 97-106, doi:10.1002/esp.2024.

Assouline, S. (2004), Rainfall-induced soil surface sealing: A critical review of observations, conceptual models, and solutions, Vadose Zone J., 3(2), 570-591, doi:10.2113/3.2.570.

Cheng, N. S. (1997), Simplified settling velocity formula for sediment particle, J. Hydraul. Eng., 123(2), 149-152.

De Roo, A. P. J., C. G. Wesseling, and C. J. Ritsema (1996), LISEM: A single-event physically based hydrological and soil erosion model for drainage basins. I: Theory, input and output, Hydrol. Processes, 10(8), 1107-1117.

Elliot, W. J., A. M. Liebenow, J. M. Laflen, and K. D. Kohl (1989), A compendium of soil erodibility data from WEPP cropland soil field erodibility experiments 1987 and 1988, NSERL Rep. 3, U. S. Dep. of Agric., West Lafayette, Indiana. 
Engman, E. T. (1986), Roughness coefficients for routing surface runoff, $J$. Irrig. Drain. Eng., 112(1), 39-53.

Esteves, M., X. Faucher, S. Galle, and M. Vauclin (2000), Overland flow and infiltration modelling for small plots during unsteady rain: Numerical results versus observed values, J. Hydrol., 228(3-4), 265-282.

Ferguson, R. I. (2005), Estimating critical stream power for bedload transport calculations in gravel-bed rivers, Geomorphology, 70, 33-41, doi:10.1016/j.geomorph.2005.03.009.

Flanagan, D. C., and M. A. Nearing (1995), USDA water erosion prediction project: Hillslope profile and watershed model documentation, NSERL Rep. 10, Agric. Res. Serv., West Lafayette, Indiana.

Hairsine, P. B., and C. W. Rose (1991), Rainfall detachment and deposition: Sediment transport in the absence of flow-driven processes, Soil Sci. Soc.Am. J., 55(2), 320-324.

Hairsine, P. B., and C. W. Rose (1992a), Modeling water erosion due to overland flow using physical principles: 1. Sheet flow, Water Resour. Res., 28(1), 237-243.

Hairsine, P. B., and C. W. Rose (1992b), Modeling water erosion due to overland flow using physical principles: 2. Rill flow, Water Resour. Res., 28(1), 245-250.

Hairsine, P. B., G. C. Sander, C. W. Rose, J.-Y. Parlange, W. L. Hogarth, I. Lisle, and H. Rouhipour (1999), Unsteady soil erosion due to rainfall impact: A model of sediment sorting on the hillslope, J. Hydrol., 220(34), 115-128, doi:10.1016/S0022-1694(99)00068-2.

Heng, B. C. P., G. C. Sander, and C. F. Scott (2009), Modeling overland flow and soil erosion on nonuniform hillslopes: A finite volume scheme, Water Resour. Res., 45, W05423, doi :10.1029/2008WR007502.

Heng, B. C. P., J. H. Chandler, and A. Armstrong (2010), Applying close range digital photogrammetry in soil erosion studies, Photogramm. Rec., 25, 240-265, doi:10.1111/j.1477-9730.2010.00584.x.

Huang, C., L. K. Wells, and L. D. Norton (1999), Sediment transport capacity and erosion processes: Model concepts and reality, Earth Surf. Processes Landforms, 24(6), 503-516, doi:10.1002/(SICI)10969837(199906)24:6\%3C503: :AID-ESP972\%3E3.0.CO;2-T.

Jetten, V., G. Govers, and R. Hessel (2003), Erosion models: Quality of spatial predictions, Hydrol. Processes, 17(5), 887-900, doi:10.1002/hyp.1168.

Lawrence, D. S. L. (1997), Macroscale surface roughness and frictional resistance in overland flow, Earth Surf. Processes Landforms, 22(4), 365-382, doi:10.1002/(SICI)1096-9837(199704)22:4\%3C365::AIDESP693\%3E3.0.CO;2-6.

Le Bissonnais, Y., B. Renaux, and H. Delouche (1995), Interactions between soil properties and moisture content in crust formation, runoff and interrill erosion from tilled loess soils, Catena, 25(1-4), 33-46, doi:10.1016/0341-8162(94)00040-L.

Leguédois, S., and Y. Le Bissonnais (2004), Size fractions resulting from an aggregate stability test, interrill detachment and transport, Earth Surf. Processes Landforms, 29(9), 1117-1129, doi:10.1002/esp.1106.

Lisle, I. G., C. W. Rose, W. L. Hogarth, P. B. Hairsine, G. C. Sander, and J.-Y. Parlange (1998), Stochastic sediment transport in soil erosion, J. Hydrol., 204(1-4), 217-230, doi:10.1016/S0022-1694(97)00123-6.

Mamedov, A. I., C. Huang, and G. J. Levy (2006), Antecedent moisture content and aging duration effects on seal formation and erosion in smectitic soils, Soil Sci. Soc. Am. J., 70, 832-843, doi:10.2136/sssaj2004.0391.

McDowell, L., G. Willis, and C. Murphree (1989), Nitrogen and phosphorus yields in run-off from silty soils in the Mississippi Delta, U.S.A., Agric., Ecosyst. Environ., 25(2-3), 119-137, doi:10.1016/0167-8809(89) 90045-5.

Mutchler, C. K., and L. M. Hansen (1970), Splash of a waterdrop at terminal velocity, Science, 169(3952), 1311-1312, doi:10.1126/science. 169.3952.1311.

Mutchler, C. K., and K. C. McGregor (1983), Erosion from low slopes, Water Resour. Res., 19(5), 1323-1326, doi:10.1029/WR019i005p01323.

Osterkamp, W. R., and T. J. Toy (1997), Geomorphic considerations for erosion prediction, Environ. Geol., 29(3/4), 152-157.

Parsons, A. J., A. D. Abrahams, and S.-H. Luk (1991), Size characteristics of sediment in interrill overland flow on a semiarid hillslope, southern $\mathrm{Ar}$ izona, Earth Surf. Processes Landforms, 16(2), 143-152, doi:10.1002/ esp.3290160205.

Proffitt, A. P. B., C. W. Rose, and P. B. Hairsine (1991), Rainfall detachment and deposition: Experiments with low slopes and significant water depths, Soil Sci. Soc. Am. J., 55(2), 325-332.

Quinton, J. N., and J. A. Catt (2007), Enrichment of heavy metals in sediment resulting from soil erosion on agricultural fields, Environ. Sci. Technol., 41, 3495-3500, doi:10.1021/es062147h.
Rauws, G. (1988), Laboratory experiments on resistance to overland flow due to composite roughness, J. Hydrol., 103(1-2), 37-52, doi:10.1016/ 0022-1694(88)90004-2.

Rojas, R., M. Velleux, P. Y. Julien, and B. E. Johnson (2008), Grid scale effects on watershed soil erosion models, J. Hydrol. Eng., 13, 793-802, doi:10.1061/(ASCE)1084-0699(2008)13:9(793).

Römkens, M. J. M., K. Helming, and S. N. Prasad (2001), Soil erosion under different rainfall intensities, surface roughness, and soil water regimes, Catena, 46(2-3), 103-123, doi:10.1016/S0341-8162(01)00161-8.

Rose, C. W., B. Yu, W. L. Hogarth, A. E. Okom, and H. Ghadiri (2003), Sediment deposition from flow at low gradients into a buffer strip-a critical test of re-entrainment theory, J. Hydrol., 280(1-4), 33-51, doi:10.1016/S0022-1694(03)00184-7.

Rose, C. W., B. Yu, H. Ghadiri, H. Asadi, J. Y. Parlange, W. L. Hogarth, and J. Hussein (2007), Dynamic erosion of soil in steady sheet flow, $J$. Hydrol., 333, 449-458, doi:10.1016/j.jhydrol.2006.09.016.

Sander, G. C., P. B. Hairsine, C. W. Rose, D. Cassidy, J.-Y. Parlange, W. L. Hogarth, and I. G. Lisle (1996), Unsteady soil erosion model, analytical solutions and comparison with experimental results, J. Hydrol., 178(14), 351-367, doi:10.1016/0022-1694(95)02810-2.

Sander, G. C., J. Y. Parlange, D. A. Barry, M. B. Parlange, and W. L. Hogarth (2007), Limitation of the transport capacity approach in sediment transport modeling, Water Resour. Res., 43, W02403, doi:10.1029/ 2006 WR005177.

Schultz, J. P., A. R. Jarrett, and J. R. Hoover (1985), Detachment and splash of a cohesive soil by rainfall, Trans. ASAE, 28(6), 1878-1884.

Sharpley, A. N. (1980), The enrichment of soil phosphorus in runoff sediments, J. Environ. Qual., 9(3), 521-526.

Strauss, P., J. Pitty, M. Pfeffer, and A. Mentler (2000), Rainfall simulation for outdoor experiments, in Current Research Methods to Assess the Environmental Fate of Pesticides, edited by P. Jamet and J. Cornejo, pp. 329-333, INRA Ed., Paris.

Sutherland, R. A., Y. Wan, A. D. Ziegler, C. T. Lee, and S. A. El-Swaify (1996), Splash and wash dynamics: An experimental investigation using an oxisol, Geoderma, 69(1-2), 85-103, doi:10.1016/0016-7061(95) 00053-4.

Tayfur, G., M. L. Kavvas, R. S. Govindaraju, and D. E. Storm (1993), Applicability of St. Venant equations for two-dimensional overland flows over rough infiltrating surfaces, J. Hydraul. Eng., 119(1), 5163.

Torri, D., M. Sfalanga, and M. Del Sette (1987), Splash detachment: Runoff depth and soil cohesion, Catena, 14(1-3), 149-155, doi:10.1016/ S0341-8162(87)80013-9.

Tromp-van Meerveld, H. J., J.-Y. Parlange, D. A. Barry, M. F. Tromp, G. C. Sander, M. T. Walter, and M. B. Parlange (2008), Influence of sediment settling velocity on mechanistic soil erosion modeling, Water Resour. Res., 44, W06401, doi:10.1029/2007WR006361.

Van Oost, K., L. Beuselinck, P. B. Hairsine, and G. Govers (2004), Spatial evaluation of a multi-class sediment transport and deposition model, Earth Surf. Processes Landforms, 29(8), 1027-1044, doi:10.1002/esp.1089.

Walker, J. D., M. T. Walter, J.-Y. Parlange, C. W. Rose, H. J. Tromp-van Meerveld, B. Gao, and A. M. Cohen (2007), Reduced raindrop-impact driven soil erosion by infiltration, J. Hydrol., 342(3-4), 331-335, doi:10.1016/j.jhydrol.2007.06.003.

Woolhiser, D. A., R. E. Smith, and D. C. Goodrich (1990), KINEROS, a kinematic runoff and erosion model: Documentation and user manual, Agric. Res. Serv., U. S. Dep. of Agric. Rep. ARS-77.

Zhang, M. K., Z. L. He, D. V. Calvert, P. J. Stoffella, X. E. Yang, and Y. C. Li (2003), Phosphorus and heavy metal attachment and release in sandy soil aggregate fractions, Soil Sci. Soc. Am. J., 67(4), 1158-1167.

Zhang, W., and T. W. Cundy (1989), Modeling of two-dimensional overland flow, Water Resour. Res., 25(9), 2019-2035, doi:10.1029/ WR025i009p02019.

A. Armstrong, School of Geographical and Earth Sciences, University of Glasgow, Glasgow GS12 8QQ, UK.

J. H. Chandler, G. C. Sander, C. F. Scott, Department of Civil and Building Engineering, Loughborough University, Loughborough LE11 3TU, UK.

B. C. P. Heng, Department of Geosciences, University of Arizona, Tucson, AZ 85721, USA. (bcpheng@email.arizona.edu)

J. N. Quinton, Lancaster Environment Centre, Lancaster University, Lancaster LA1 4YQ, UK. 